University of Nebraska - Lincoln

DigitalCommons@University of Nebraska - Lincoln

2009

\title{
Not all Conscientiousness Scales Change Alike: A Multimethod, Multisample Study of Age Differences in the Facets of Conscientiousness
}

\author{
Joshua J. Jackson \\ University of Illinois at Urbana-Champaign \\ Tim Bogg \\ Indiana University \\ Kate E. Walton \\ St. John's University \\ Dustin Wood \\ Wake Forest University \\ Peter D. Harms \\ University of Nebraska - Lincoln, pharms@gmail.com
}

See next page for additional authors

Follow this and additional works at: https://digitalcommons.unl.edu/leadershipfacpub

Part of the Management Sciences and Quantitative Methods Commons

Jackson, Joshua J.; Bogg, Tim; Walton, Kate E.; Wood, Dustin; Harms, Peter D.; Lodi-Smith, Jennifer; Edmonds, Grant W.; and Roberts, Brent W., "Not all Conscientiousness Scales Change Alike: A Multimethod, Multisample Study of Age Differences in the Facets of Conscientiousness" (2009). Leadership Institute Faculty Publications. 5.

https://digitalcommons.unl.edu/leadershipfacpub/5

This Article is brought to you for free and open access by the Leadership Institute at DigitalCommons@University of Nebraska - Lincoln. It has been accepted for inclusion in Leadership Institute Faculty Publications by an authorized administrator of DigitalCommons@University of Nebraska - Lincoln. 


\section{Authors}

Joshua J. Jackson, Tim Bogg, Kate E. Walton, Dustin Wood, Peter D. Harms, Jennifer Lodi-Smith, Grant W. Edmonds, and Brent W. Roberts 
Published in Journal of Personality and Social Psychology 96:2 (2009), pp. 446-459; doi: 10.1037/a0014156

Copyright (c) 2009 American Psychological Association. Used by permission. "This article may not exactly replicate the final version published in the APA journal. It is not the copy of record."

Preparation of this article was supported by National Institute of Aging Grant RO1 AG21178 and a graduate research fellowship from the National Science Foundation awarded to Joshua J. Jackson.

\title{
Not all Conscientiousness Scales Change Alike: A Multimethod, Multisample Study of Age Differences in the Facets of Conscientiousness
}

\author{
Joshua J. Jackson, ${ }^{1}$ Tim Bogg, ${ }^{2}$ Kate E. Walton, ${ }^{3}$ Dustin Wood, ${ }^{4}$ Peter D. Harms, ${ }^{5}$ \\ Jennifer Lodi-Smith, ${ }^{6}$ Grant W. Edmonds, ${ }^{1}$ and Brent W. Roberts ${ }^{1}$ \\ ${ }^{1}$ Department of Psychology, University of Illinois at Urbana-Champaign \\ ${ }^{2}$ Department of Psychological and Brain Sciences, Indiana University, Bloomington \\ ${ }^{3}$ Psychology Department, St. John's University \\ ${ }^{4}$ Department of Psychology, Wake Forest University \\ ${ }^{5}$ Department of Management, University of Nebraska-Lincoln \\ ${ }^{6}$ Center for Brain Health, School of Behavioral and Brain Sciences, University of Texas at Dallas \\ Corresponding author - Joshua J. Jackson, Department of Psychology, University of Illinois at Urbana-Champaign, \\ Champaign, IL 61820; email jjackso7@uiuc.edu
}

\begin{abstract}
Previous research has shown that traits from the domain of conscientiousness tend to increase with age. However, previous research has not tested whether all aspects of conscientiousness change with age. The present research tests age differences in multiple facets of conscientiousness (industriousness, orderliness, impulse control, reliability, and conventionality) using multiple methods and multiple samples. In a community sample $(N$ $=274)$ and a representative statewide sample $(N=613)$ of 18 - to 94-year-olds, self-reported industriousness, impulse control, and reliability showed age differences from early adulthood to middle age, whereas orderliness did not. The transition into late adulthood was characterized by increases in impulse control, reliability, and conventionality. In contrast, age differences in observer-rated personality occurred mainly in older adulthood. Age differences held across both ethnicity and levels of socioeconomic status.
\end{abstract}

Keywords: conscientiousness, personality development, facets, age differences, observer reports

The personality trait of conscientiousness refers to the propensity to follow socially prescribed norms and rules, to be goal-directed, planful, able to delay gratification, and to control impulses (John \& Srivastava, 1999). Both cross-sectional and longitudinal studies show that people become more conscientious with age and that these increases often occur quite late in the life course (Helson \& Kwam, 2000; Helson \& Wink, 1992; Roberts, Walton, \& Viechtbauer, 2006; Srivastava, John, Gosling, \& Potter, 2003). For example, numerous cross-sectional studies have demonstrated that older individuals are higher in conscientiousness than younger individuals. In five different cultures, individuals past the age of 30 were more conscientious than younger individuals (McCrae et al., 1999). A closer examination of this cross-sectional pattern in a large Internet sample found that conscientiousness increases in each decade of life up to age 60 (Srivastava et al., 2003).

Multiple longitudinal studies also have shown increases in conscientiousness with age. Changes in conscientiousness were analyzed in a meta-analysis of 92 longitudinal studies spanning the period from age 10 to 101 years (Roberts, Walton, \& Viechtbauer, 2006). Traits belonging to the domain of conscientiousness increased in young adulthood (age 20-40), middle 
age (40-50) and old age (60-70). Several aspects of these metaanalytic findings are important to highlight. First, the effects were heterogeneous, which means that despite the general upward trend, some studies did not find increases in conscientiousness with age (e.g., Costa \& McCrae, 1988). Furthermore, the effect sizes were modest within decades. However, when accumulated across the life span, conscientiousness increased a full standard deviation from young adulthood through old age. These results strongly suggest that traits from the domain of conscientiousness increase throughout the life course.

Changes in conscientiousness are important when one considers the relevance of conscientiousness both to society and to the individual. From a societal perspective, people who are highly conscientious are less likely to commit crimes (Miller \& Lynam, 2001) and more likely to be committed to and involved with their work, family, and community (Lodi-Smith \& Roberts, 2007). At the individual level, conscientiousness is related to more effective functioning in multiple domains such as marriage (Roberts \& Bogg, 2004), work (Judge, Martocchio, \& Thoresen, 1997), and health (Friedman et al., 1993; Roberts, Walton, \& Bogg, 2005). The predictive validity of conscientiousness for outcomes such as mortality and divorce is on par with cognitive abilities or socioeconomic status (SES; Roberts, Kuncel, Shiner, Caspi, \& Goldberg, 2007). In addition, it is possible that changes in conscientiousness are important above and beyond where a person stands on conscientiousness at any given time. For example, two studies have shown that changes in personality traits predict health and longevity above and beyond initial levels of personality (Mroczek \& Spiro, 2007; Siegler et al., 2003). This means that changes in conscientiousness could have profound effects on the well-being of individuals.

Despite the accumulating evidence that conscientiousness increases with age and that changes in personality are important to life outcomes, there are a number of questions about the development of conscientiousness that have yet to be addressed. First, most cross-sectional and longitudinal studies have focused at a broad level of analysis and have not examined change in the subscales or facets of conscientiousness (e.g., Srivastava et al., 2003). This may be one reason for the heterogeneity in the meta-analytic findings. Different measures of conscientiousness tend to emphasize different aspects of the conscientiousness domain (Roberts, Chernyshenko, Stark, \& Goldberg, 2005). Some measures, such as the Revised NEO Personality Inventory (NEO-PI-R; Costa \& McCrae, 1992) and Goldberg's Abridged Big Five Dimensional Circumplex (AB5C; Goldberg, 1999) emphasize the industriousness and orderliness aspects of conscientiousness, whereas other measures, such as the Multidimensional Personality Questionnaire (Tellegen \& Waller, 1994), emphasize the self-control aspect of conscientiousness. Some short measures of personality, such as the Big Five Inventory (John \& Srivastava, 1999) or the NEO Five-Factor Inventory (NEO-FFI; Costa \& McCrae, 1992) have relatively unknown coverage of the specific aspects of conscientiousness. In contrast, the Conscientiousness scale from the Big Five Mini-Markers measure (Saucier, 1994) focuses almost exclusively on orderliness.

Without a systematic assessment of the full domain of conscientiousness, the resulting developmental picture may be biased by the idiosyncratic nature of the personality inventories used in cross-sectional and longitudinal research. Increases in conscientiousness may be a result of all facets changing in con- cert or specific facets changing dramatically, whereas other facets change little. Differences between facet trajectories are masked when viewing personality trait change at the broad Big Five level of analysis, as in the meta-analysis of mean-level changes in personality (Roberts, Walton, \& Viechtbauer, 2006) or in studies in which abbreviated measures of the Big Five are used (e.g., Srivastava et al., 2003).

The domain of extraversion provides the most salient example of how failing to differentiate the underlying structure of the domain can lead to misleading results and conclusions. Most undifferentiated examinations of changes in extraversion show little or no change with age (e.g., McCrae et al., 1999). In contrast, Helson and Kwan (2000) pointed out that the social dominance facet of extraversion (e.g., assertiveness, ambition, dominance) increases with age, whereas the social vitality facet (e.g., talkativeness, sociability, gregariousness) decreases. Consistent with this argument, when examined separately, traits from the domain of social dominance showed some of the largest changes found in any trait domain, whereas traits from the social vitality domain showed little change (Roberts, Walton, \& Viechtbauer, 2006). Without distinguishing between these two aspects of extraversion, overall patterns are misleading.

This leads to the obvious question: What is the lower order structure of conscientiousness? One route to identifying the structure of conscientiousness is to examine lexically derived trait adjectives, as was done to develop the Big Five (e.g., Goldberg, 1993). A second route to identifying the underlying domain of conscientiousness is an examination of the factor structure of existing personality inventories that measure conscientiousness-related traits. In the search for the Big Five, a systematic analysis of previously developed personality inventories provided much needed confirmation that the Big Five was an appropriate taxonomy for the domain of personality traits (McCrae \& John, 1992).

The first study to identify the lower order structure of conscientiousness used a broad sample of conscientiousness adjectives (Roberts, Bogg, Walton, Chernyshenko, \& Stark, 2004). Seven facets emerged: orderliness, industriousness, reliability, decisiveness, impulse control, formalness, and conventionality. A second study examined the factor structure of 36 different scales assessing aspects of conscientiousness, drawn from seven major personality inventories, which included the most widely used questionnaires in existence (e.g., the NEO-PI$\mathrm{R}$, California Psychological Inventory, Multidimensional Personality Questionnaire, and the like; Roberts, Chernyshenko, et al., 2005). The 36 measures of conscientiousness were best subsumed by six factors: impulse control, conventionality, reliability, industriousness, order, and virtue.

Interestingly, there was striking convergence across the lexical and questionnaire studies. Industriousness (tenacious vs. lazy), orderliness (organized vs. sloppy), impulse control (cautious vs. careless), reliability (dependable vs. unreliable), and conventionality (traditional vs. nonconforming) replicated across these disparate samples and assessment techniques. It appears that, at the minimum, there exist five facets of conscientiousness (see Table 1).

Two aspects of this five-facet interpretation of conscientiousness are worth noting. First, no existing personality measure includes all five facets, which renders any existing system of assessing conscientiousness inadequate (Roberts, Chernyshenko, et al., 2005). Second, in both studies these facets of con- 
Table 1. Five Facets of Conscientiousness

\begin{tabular}{ll}
\hline Facet & Description \\
\hline $\begin{array}{l}\text { Industriousness } \\
\text { Orderliness }\end{array}$ & $\begin{array}{l}\text { The propensity to work hard versus being lazy } \\
\text { The propensity to be organized and neat versus } \\
\text { being messy }\end{array}$ \\
Impulse Control & $\begin{array}{r}\text { The propensity to inhibit prepotent responses } \\
\text { versus being careless }\end{array}$ \\
Reliability & $\begin{array}{r}\text { The propensity to be responsible and dependable } \\
\text { versus being unreliable }\end{array}$ \\
Conventionality & $\begin{array}{r}\text { The propensity to follow socially proscribed } \\
\text { norms and versus being untraditional }\end{array}$ \\
\hline
\end{tabular}

scientiousness showed good levels of convergent and discriminant validity with the remaining Big Five, with the exception of the reliability facet. The latter is almost equivalently correlated with conscientiousness and agreeableness. Conventionality, often thought to belong to the domain of openness to experience, was strongly correlated with conscientiousness and only weakly correlated with openness to experience. It remains to be seen whether the age changes in conscientiousness are pervasive across all facets of conscientiousness or are particular to just a few, an issue we address directly in Study 1.

The second omission from previous research is that most personality development research has failed to test measurement equivalence of personality across age groups and time. One of the most important preliminary steps in a developmental study is to determine whether the constructs being assessed change their meaning across different age groups. If the measure does not assess the same construct across different age groups, then any comparisons across age groups would be misleading. The most common test is to compare the factor structure of the measures across age and time through confirmatory factor analysis (Meredith, 1993). The findings for tests of the structural invariance of personality measures across different age groups have been mixed. Some studies show strict measurement invariance (Allemand, Zimprich, \& Hertzog, 2007), but some have not, especially when examining older samples (Small, Hertzog, Hultsch, \& Dixon, 2003). Needless to say, no study has examined the structure of conscientiousness facets over the life course, nor has any study examined measurement invariance in observer reports. We address this issue across both studies.

Third, most developmental studies of conscientiousness have been based on only one method of measurement, and typically that method is self-report. Very few studies have simultaneously used multiple methods, such as self-reports and observer reports, to test age changes in personality. Collecting both self-reported and observer measures of personality provides a unique data set to test whether the age differences, most often found in self-reports, also are seen in observer ratings of personality. Although self-reports and observer reports of personality traits purport to assess the same construct, the two approaches are not completely redundant (Fiske, 1971; Roberts, Harms, Smith, Wood, \& Webb, 2006). Depending on the context, observer reports or self-reports may predict behavior better (Kolar, Funder, \& Colvin, 1996; Spain, Eaton, \& Funder, 2000), or they may predict complementary variance (Mount, Barrick, \& Strauss, 1994). The implication here is that the two methods may yield different but meaningful information about the development of conscientiousness.
Because there are so few studies in which age differences in observer ratings of personality are examined, a consensus for the patterns of change has yet to emerge. McCrae et al. (2004) found that age differences in observer ratings of personality were similar in direction but smaller in magnitude than self-reports. Other studies have found a striking discrepancy between self- and observer reports, in which the direction of change in observer reports is opposite from selfreports (Watson \& Humrichouse, 2006). Additionally, there is a paucity of data that tracks age differences in observerreported personality traits across different periods in the life course, especially in late adulthood. This issue is also addressed in Study 1.

A fourth potential problem of much personality development research is that few, if any, studies use a sampling technique that guarantees a representative sample of individuals. A disproportionate number of cross-sectional or longitudinal studies have examined trait development in highly educated, middle- to upper-class, predominantly Caucasian samples (Roberts, Walton, \& Viechtbaeur, 2006). Before these patterns of development can be generalized, it would be prudent to test whether the increases in conscientiousness replicate in representative samples. One of the conspicuous omissions in the published literature is that little is known about how differences in ethnicity or SES contribute to personality development. Replicating patterns of development in diverse samples is important to the generalization of the patterns of change demonstrated so far. We address this issue in Study 2.

To address the omissions in the literature, we initiated two large-scale studies to examine mean-level changes in conscientiousness throughout adulthood. In Study 1, we used multiple measures and multiple methods to track age differences using the five-facet-level model of conscientiousness. In Study 2, we assessed several facets of conscientiousness using a representative, age-stratified sample of Illinois. This provided a large enough sample of ethnic minorities and a diverse range of SES to examine the development of conscientiousness in these understudied populations.

\section{Study 1}

\section{Method}

Participants and procedure. One hundred sixty-eight female and 106 male $(N=274)$ community members participated in Study 1. Participants ranged from 19 to 94 years of age $(M=$ $51.25, S D=16.43$ ), consisting of $6 \%$ African American, $2 \%$ Hispanic/Chicano/Mexican American, 2\% Asian, 88\% Caucasian, and $2 \%$ listed as "other."

To examine age-related mean-level differences in conscientiousness, participants were split into three age groups. These age groups were based on divisions used in lifespan development that identify young, middle, and older adulthood as important age categories in the lifespan (e.g., Heckhausen, Dixon, \& Baltes, 1989). Specifically, The Mid-life in the United States (MIDUS; Brimm, 2000) study defines the core of middle age as the years between 40 and 60 . Adults under 40 are traditionally assigned to young adulthood status, with possible finer grain distinctions made for a college-age group. Individuals over 60 fall into the category of older adulthood, which likewise can 
be more finely divided into young-old and oldest-old (Baltes \& Smith, 2003). Following this tradition, we classified individuals 19-39 years of age as young adults $(n=76), 40$ - to 59-yearolds as middle-aged $(n=124)$, and individuals 60 and older as older adults $(n=74)$. Participants were part of the community subsample of the Health and Aging Study of Central Illinois (HASCI). Participants were solicited from various sources such as fliers around the community and advertisements in the local newspaper. Participants completed the McAdams' Life Story Interview (McAdams, 1993) as well as questionnaires on personality and health and were reimbursed $\$ 8-\$ 10$ per hour for their time.

Measures of conscientiousness. In order to assess all five facets of conscientiousness, two different measures of conscientiousness were used. The five facets were measured directly with the five scales from the Conscientiousness Adjective Checklist (CAC; Roberts et al., 2004). The CAC was developed in an attempt to cover the full domain of conscientiousness. The five scales from the CAC were selected that replicated across the two studies and that identified the lower order structure of conscientiousness (Roberts, Walton, \& Bogg, 2005): Industriousness, Orderliness, Impulse Control, Reliability, and Conventionality. ${ }^{1}$ Participants rated the adjectives on a 5-point scale ranging from 1 (strongly disagree) to 5 (strongly agree). Reliabilities for each scale were good, ranging from .65 to .87 , with a mean of .78 .

In addition, participants completed the nine conscientiousness scales from the 485-item version of the International Personality Item Pool (IPIP)-AB5C (Goldberg, 1999). The development of the IPIP-AB5C was based on the ubiquitous two-factor nature of most trait adjectives (Hofstee, de Raad, \& Goldberg, 1992). Specifically, most personality trait descriptors are blends of two factors rather than one discreet factor. Thus, trait terms and personality inventory items can be organized around circumplex structures. For example, all of the Big Five dimensions can be combined into two-factor circumplex structures and examined to see how specific aspects of personality blend with each other.

Goldberg (1999) used these circumplex structures as a basis for writing items for subscales for each of the Big Five. For the domain of conscientiousness, there is a core facet that reflects the presumed "pure" items that reflect where the factor falls. The remaining eight facets reflect the blends of conscientiousness and the remaining four Big Five (e.g., high and low extraversion with conscientiousness). The term blend is not meant to indicate that each trait domain is equally weighted in the derivation of the facet scale. Rather, the eight blend facets reflect very slight blends with the remaining Big Five, such that the eight facets correlate predominantly with conscientiousness and only slightly with the remaining Big Five. At least at a conceptual level, this is the best articulated and substantiated system for developing a measure of the Big Five because it reflects the reality that most personality trait descriptors are not unidimensional. The nine AB5C Conscientiousness facets are Conscientiousness (III+/III+), Efficiency (III+/I+), Cautiousness (III+/I), Dutifulness $(\mathrm{III}+/ \mathrm{II}+)$, Rationality (III+/II-), Purposefulness (III+/IV+), Perfectionism (III+/IV-), Organization (III+/V+), and Orderliness (III+/V-). Participants rated the AB5C items on a 5-point scale ranging from 1 (strongly disagree) to 5 (strongly agree). Reliabilities ranged from .67 to .90 , with a mean of .80 .
Despite the relatively well-articulated system for mapping out the lower order structure of conscientiousness inherent in the $\mathrm{AB} 5 \mathrm{C}$ system, empirical evidence has shown that the nine $\mathrm{AB} 5 \mathrm{C}$ facet scales do not capture the full range of the lower order structure of conscientiousness (Roberts, Chernyshenko, et al., 2005). Specifically, Roberts, Chernyshenko, et al. (2005) found that the conscientiousness scales from the $\mathrm{AB} 5 \mathrm{C}$ mainly tap the Industriousness and Orderliness facets of conscientiousness, with a single scale measuring the Impulse Control facet and no scales tapping reliability or conventionality facets. In contrast, the $\mathrm{CAC}$ measure does contain dimensions that reflect the five replicable underlying facets of conscientiousness. Therefore, the findings of Roberts, Chernyshenko, et al. (2005) were used to classify each scale of the AB5C and CAC into one of the five facets of conscientiousness. ${ }^{2}$ The AB5C scales of Organization, Purposefulness, Efficiency, Rationality and Dutifulness, as well as the Industriousness scale of the CAC, were used to measure the industriousness facet. The orderliness facet included the scales of Orderliness, Conscientiousness, and Perfectionism from the AB5C and the Orderliness scale from the CAC. The impulse control facet consisted of the AB5C Cautiousness scale and the Impulse Control scale from the CAC. The Reliability scale of the CAC measured the reliability facet, and the CAC scale of Conventionality measured the conventionality facet. Correlations between conscientiousness scales are presented in Table 2. The choice to aggregate scales within each facet was made to give a composite score for each facet of conscientiousness.

Observer ratings. Observers rated each participant's personality using the CAC. Observer reports of personality were obtained by three different methods. First, after the McAdams Life History Interview was conducted, the interviewer rated the participant with the CAC. Second, research assistants unacquainted with the participant listened to an audio recording of the Life History Interview and rated the participant with the CAC. Lastly, close associates of the participant were contacted and mailed the CAC as part of a large packet of questionnaires about the participant. Close associates knew the participants on average 28 years $(S D=21.4)$. Roughly half the participants $(n=146)$ had at least one close associate rating (total number of ratings $=236$ ). There were no large differences in self-report personality between individuals who had a close associate rating versus those who did not. Results across different types of observers were collapsed to create a composite observer measure.

A total of 1,023 observer reports were obtained, with each participant having between 2 and 6 ratings, with the modal number of 4 ratings per participant. The average interrater correlation across all facets was .44. Applying the Spearman-Brown prophecy formula to each scale's average interrater correlation and solving for the modal number of 4 raters resulted in an average reliability of .80 for the observer facet measures. All scales showed good internal reliability, with all being above .70. Using the minimum of two raters, the average reliability was .64, with industriousness having the lowest reliability (.56), whereas solving for the maximum of six raters gave an average reliability of .84 . Only a small number of participants had two observer ratings, the majority had three or four observer ratings.

1. The scales of formalness, decisiveness, foolhardiness, and punctuality were not included in the present analyses.

2. We fit this structure to our data and found that this structure fit the data adequately. 
Table 2. Correlations Between Conscientiousness Scales in Study 1

\begin{tabular}{|c|c|c|c|c|c|c|c|c|c|c|c|c|c|c|}
\hline Scale & 1 & 2 & 3 & 4 & 5 & 6 & 7 & 8 & 9 & 10 & 11 & 12 & 13 & 14 \\
\hline 2. AB5C Purposefulness & .53 & .84 & & & & & & & & & & & & \\
\hline 4. AB5C Efficiency & .56 & .86 & .59 & .83 & & & & & & & & & & \\
\hline 5. AB5C Organization & .55 & .59 & .58 & .64 & .86 & & & & & & & & & \\
\hline 6. AB5C Conscientiousness & .51 & .74 & .67 & .75 & .70 & .76 & & & & & & & & \\
\hline 8. AB5C Orderliness & .36 & .53 & .62 & .55 & .58 & .64 & .60 & .79 & & & & & & \\
\hline 9. AB5C Rationality & .43 & .43 & .26 & .44 & .47 & .44 & .36 & .38 & .62 & & & & & \\
\hline 10. AB5C Perfectionism & .31 & .19 & .25 & .25 & .54 & .36 & .33 & .53 & .41 & .80 & & & & \\
\hline 11. CAC Impulse Control & .56 & .53 & .53 & .52 & .56 & .57 & .46 & .50 & .30 & .31 & .75 & & & \\
\hline 12. AB5C Cautiousness & .35 & .40 & .39 & .32 & .33 & .46 & .29 & .39 & .31 & .23 & .55 & .73 & & \\
\hline 13. CAC Reliability & .49 & .56 & .47 & .51 & .43 & .54 & .36 & .36 & .25 & .13 & .53 & .23 & .77 & \\
\hline
\end{tabular}

$\mathrm{CAC}=$ Conscientiousness Adjective Checklist; $\mathrm{AB5C}=$ Abridged Big Five Dimensional Circumplex.

Overview of statistical analyses. Because comparisons across age groups rely on the assumption that conscientiousness has the same meaning across each age group, Measurement equivalence of the conscientiousness measures was first tested. A multiple-group confirmatory factor analysis (CFA) was used to test measurement invariance across age groups. Measurement equivalence was examined by testing each scale associated with the five replicable facets of conscientiousness. For the individual scales, three parcels were used as indicators rather than single items to better meet the assumption of normal distribution for maximum-likelihood parameter estimation. Parcels were built by averaging several items, according to the item-to-construct technique (Little, Cunningham, Shahar, \& Widaman, 2002).

Different degrees of measurement invariance were investigated, with each step offering a more restrictive level of measurement invariance (Vandenberg \& Lance, 2000). The first step, configural invariance, assesses the extent to which the number of factors is consistent across age groups. The second step, metric invariance, constrains the factor loadings of the groups to be identical. The last step, scalar invariance, additionally constrains the measurement intercepts to be equal across groups. Model fit was assessed by the incremental fit index (IFI) and root-mean-square error of approximation (RMSEA; Hu \& Bentler, 1999). Nested models were compared by chi-square difference tests and overlap of $95 \%$ confidence intervals around RMSEA estimates (MacCallum, Browne, \& Sugawara, 1996). Weak measurement invariance is said to exist when the additional constraints of the metric invariance model do not significantly reduce configural model fit. However, to meaningfully compare age differences, the additional constraints of scalar invariance must also preserve model fit. This requirement is referred to as strict measurement invariance (Horn \& McArdle, 1992).

In cases in which the prerequisite of strict measurement invariance was met, age differences in conscientiousness were examined next. Differences between the three age groups were estimated using Cohen's $d$ statistic by dividing the mean difference between age groups with the pooled standard deviation of each scale (Cohen, 1992). Ninety-five percent confidence intervals around the $d$ estimate were calculated using a bootstrapping procedure. ${ }^{3}$ Additionally, one-way analyses of variance (ANOVAs) were examined with least significant difference post hoc contrasts to test whether significant meanlevel differences occurred across the three age groups. ${ }^{4}$ Consistent with past results (Helson, Pals, \& Solomon, 1997; Roberts, Caspi, \& Moffitt, 2001, Roberts, Walton, \& Viechtbauer, 2006), preliminary analyses indicated no evidence of a Gender $\times$ Age interaction for any facet. As a result, women and men were combined for all analyses. In addition to examining mean-level differences, each scale was regressed on age and age squared to test the linear and curvilinear effects of age.

\section{Results}

Measurement invariance. First, we tested the measurement equivalence of each of the 14 scales separately. We first tested for configural invariance, which does not include any parameter constraints across age groups. Each scale of the AB5C and the CAC achieved an acceptable fit, with IFIs above .90 (average $=.98$ ) and RMSEAs below .1 (average RMSEA $=.06$ ). To examine whether weak measurement equivalence existed, we constrained item factor loadings across age groups. When compared with the configural model, the metric invariance model did not significantly reduce fit for any scale (all $\Delta \chi^{2} \mathrm{~s}, p$ $>.05$; average IFI $=.97$, average RMSEA $=.05$ ). Also, the overlap of the RMSEA confidence intervals indicated no difference in fit. Therefore, we retained the metric invariance model for all the scales. Finally, the intercepts of the manifest indicators were constrained across groups to test scalar invariance. The model fit (average IFI $=.96$, average RMSEA $=.06$ ) was indistinguishable from the previous models for all facets based

3. The $R$ script for this procedure is available from Joshua J. Jackson upon request.

4. Dividing our sample into more than three groups (e.g., decades) produced similar findings. Three age groups were retained to provide adequate power and for consistency with demographic organization of the life course. 
on nonsignificant chi-square and overlapping RMSEA confidence intervals. Taken together, these results indicate strong measurement equivalence for conscientiousness scales across groups and that differences between age groups can be interpreted meaningfully.

Measurement invariance also was examined for the observer ratings. The configural invariance model fit well for each scale (average IFI $=.98$, average RMSEA $=.09$ ). Constraining factor loadings across age groups did not reduce fit (all $\Delta \chi^{2} \mathrm{~s}, p>.05$; average IFI $=.98$, average RMSEA $=.08$ ). In the third model, measurement intercepts were constrained to be equal across groups. This did not significantly reduce fit compared with the metric model (all $\Delta \chi^{2} \mathrm{~s}, p>.05$, average IFI $=$ .97 , average RMSEA $=.08$ ). Like self-reports of conscientiousness, observer reports conform to strict measurement equivalence, making the means comparable across age groups.

Mean-level differences in self-reported conscientiousness. The mean, standard deviation, $d$-metric effect size for each facet scale, and correlation with age is presented in Table 3 for self-reported conscientiousness. The longitudinal data shows larger amounts of change in young adulthood than in middleor old age (Roberts, Walton, \& Viechtbauer, 2006). However, these overall estimates may mask more specific developmental trends in the facets of conscientiousness. To test this idea, we examined age differences at the facet level of analysis and for each scale score. ${ }^{5}$

In contrast to the age changes found using broad measures of conscientiousness, a facet level of analysis revealed unique age patterns for each facet. Like the meta-analytic estimate of age differences in conscientiousness, the scales that tap the industriousness facet differed mostly between young adulthood and middle age. The middle-aged group scored higher than the young adult group on the overall industriousness composite $(d=0.42, p<.05)$. This was driven by significant differences on the CAC Industriousness scale $(d=0.53, p<.05)$, the AB5C Purposefulness scale $(d=0.37, p<.05)$, and the AB5C Efficiency scale $(d=0.28, p<.05)$. No significant age differences on the industriousness scales were found between midlife and older adulthood.

In contrast, no significant differences between age groups were found for the orderliness facet. The overall orderliness composite showed no significant differences across age groups, and four out of five scales that measure orderliness did not differ between age groups. The lone exception, AB5C conscientiousness, showed increases from young adulthood to middle age $(d=0.29, p<.05)$. Taken together, the scales from the domain of orderliness appear to contribute little to the overall increases found in estimates based on aggregate measures of conscientiousness.

Unlike the industriousness and orderliness domains, the composite measure of impulse control increased between every age group from young adulthood to middle age $(d=0.59$, $p<.05)$ and from middle to older adulthood $(d=0.33, p<.05)$. Both scales measuring impulse control showed significant age effects between young adulthood and middle age $(d=0.60 ; d$ $=0.46, p \mathrm{~s}<.05$ ). In addition, the older adulthood group scored significantly higher than the middle-aged group on the AB5C measure of Cautiousness $(d=0.36 p<.05)$. These findings suggest that impulse control tends to increase throughout the lifespan.
The age differences for the remaining two facets of conscientiousness, reliability and conventionality, also deviated from the overall pattern found in the broad trait of conscientiousness. The reliability facet significantly increased across all three age groups. Middle-aged participants scored higher than young adults $(d=0.44, p<.05)$, and these differences continued later in the lifespan with significant differences between middle- and older aged groups $(d=0.27, p<.05)$. Conventionality had a different pattern than the other facets of conscientiousness. No significant age differences were found between young and middle age, but older-aged individuals were found to be significantly more conventional than middle-aged participants $(d=0.38, p<.05)$.

Age differences were also examined continuously by looking at both linear and curvilinear effects of age. Correlations with age for each scale replicated mean-level differences. Industriousness $(r=.18)$, impulse control $(r=.33)$, reliability $(r=.24)$, and conventionality $(r=.13)$ are all significantly correlated with age, whereas the orderliness facet was not $(r=.06, p>.05)$. A curvilinear effect was significant for the CAC Industriousness scale $(\beta=-.12, p<.05)$, where industriousness increased until middle age, plateaued, and then slightly dropped after age 80 .

Observer reports of conscientiousness facets. Next, we tested age differences in observer ratings of conscientiousness. The findings are summarized in Table 4. Surprisingly, no significant differences occurred between young and middle-aged adults across all scales. However, all the scales that significantly increased with age in self-reports also significantly increased between middle- and old age. Age differences in industriousness occurred between middle- and older age $(d=$ $0.39, p<.05)$. Mirroring self-report findings, levels of orderliness did not significantly differ across age groups. Much like self-reports, levels of impulse control were significantly higher in older age than middle age $(d=0.40, p s<.05)$, as was the facet of reliability $(d=0.45, p<.05)$. Age differences late in life also were found for the facet of conventionality, where levels of conventionality were significantly larger in older adults than in middle-aged adults $(d=0.59, p<.05)$. These mean-level findings were again corroborated by significant correlations with age. Interestingly, orderliness was significantly correlated with age $(r=.15)$, despite no significant mean-level differences in mean levels across different age groups. However, this correlation was smaller than other estimates, suggesting that observers may perceive changes in orderliness with age, but at lower levels than the remaining traits.

\section{Discussion}

In Study 1, we found a surprising level of heterogeneity in age differences across the facets of conscientiousness. On the basis of self reports, the age differences that occur for the aggregate or undifferentiated assessments of conscientiousness are the result of different facets changing at different times, with increases early in adulthood attributable mostly to changes in industriousness, whereas changes later in life result from differences in impulse control, reliability, and conventionality. Age-related changes found for measures of orderliness were small or nonexistent; indicating that the age changes found in the broad trait of conscientiousness are mostly attributable to the other aspects of conscientiousness. 
Table 3. Study 1 Age Differences: Self Report

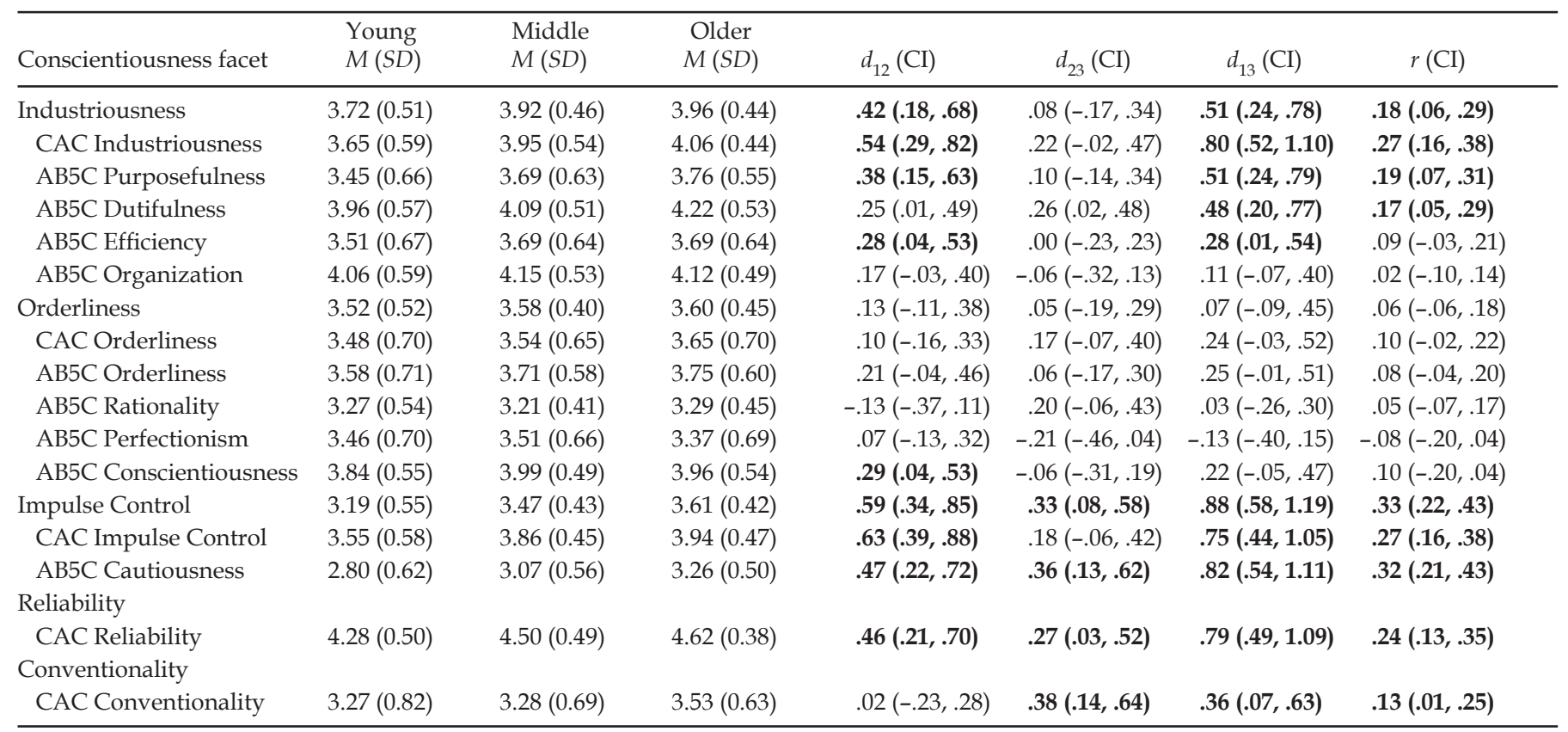

$n=76$ for Young; $n=124$ for Middle; $n=74$ for Older adulthood; $d_{12}=$ standardized mean difference between young age (20-39) and middle age (40-59); $d_{23}=$ standardized mean difference between middle age and old age (60 and above); $d_{13}=$ standardized mean difference between old-age and young-age groups; $r=$ correlation with age; $\mathrm{CI}=95 \%$ confidence intervals; $\mathrm{CAC}=$ Conscientiousness Adjective Checklist; $\mathrm{AB} 5 \mathrm{C}=\mathrm{Abridged}$ Big Five Dimensional Circumplex. Bold values indicate $p<.05$.

In contrast to self-reports, observer reports located most age differences later in the lifespan. This would appear to indicate that increases in conscientiousness are noted in both perspectives but that observers did not see these changes until people were older. It may be that shifts seen in the self take a longer time to be seen by observers.

\section{Study 2}

Study 2 was designed to replicate and extend the findings in Study 1 by using a representative, age-stratified sample of Illinois residents. A disproportionate number of personality development studies use samples of convenience and therefore may not be representative of the population at large (Roberts, Walton, \& Viechtbauer, 2006). In addition, samples of ethnic minorities and mixed SES generally have received less attention in personality research. The patterns of development for these groups could vary significantly from the typical middle- to upper-class Caucasian sample that characterizes most psychological research.
The first aim of Study 2 was to investigate the age differences in self-reported conscientiousness in a representative sample. Only the AB5C was administered in this sample, thus limiting the analysis to the facets of industriousness, orderliness, and impulse control. We expected industriousness to show similar age differences as those found in Study 1, with most increases between young adulthood and middle age. Likewise, we expected impulse control to increase across all age periods. Because orderliness exhibited little change across age groups in Study 1, we hypothesized fewer age differences for scales drawn from this domain. Second, because a representative sample of the state of Illinois allows an examination of the oft-neglected group of ethnic minorities, we tested whether age differences replicate in a group of African Americans and ethnic minorities as a whole. Third, a representative sample also allows an examination of varying levels of SES. Different levels of SES could influence the development of conscientiousness, and thus we tested whether age differences replicated in different levels of SES.

Table 4. Study 1 Age Differences: Observer Report

\begin{tabular}{|c|c|c|c|c|c|c|c|}
\hline Conscientiousness facet & Young $M(S D)$ & Middle $M(S D)$ & Older $M(S D)$ & $d_{12}(\mathrm{CI})$ & $d_{23}(\mathrm{CI})$ & $d_{13}(\mathrm{CI})$ & $r(\mathrm{CI})$ \\
\hline Orderliness & $3.50(0.56)$ & $3.53(0.64)$ & $3.63(0.51)$ & $.05(-.20, .28)$ & $.17(-.08,41)$ & $.24(-.02, .52)$ & $.15(.03, .27)$ \\
\hline Reliability & $3.99(0.63)$ & $4.05(0.65)$ & $4.29(0.40)$ & $.10(-.14, .35)$ & $.44(.19, .69)$ & $.58(.31, .89)$ & $.21(.09, .32)$ \\
\hline Conventionality & $3.25(0.62)$ & $3.35(0.64)$ & $3.69(0.44)$ & $.16(-.09, .39)$ & $.60(.34, .89)$ & $.84(.54,1.14)$ & $.29(.18, .40)$ \\
\hline
\end{tabular}

$n=76$ for Young; $n=124$ for Middle; $n=74$ for Older; $d_{12}=$ standardized mean difference between middle age (40-59) and young age (20-39); $d_{23}$ = standardized mean difference between old age ( 60 and above) and middle age; $d_{13}=$ standardized mean difference between old-age and youngage groups; $r=$ correlation with age; $C I=95 \%$ confidence intervals. Bold values indicate $p<.05$. 
Method

Participants and procedure. Six hundred thirteen participants (351 women) selected at random from around the State of Illinois participated in the Study 2. These participants comprised the statewide subsample of the Health and Aging Study of Central Illinois (HASCI). Participant age ranged from 19 to 86 years of age $(M=47.53, S D=17.71)$. Participants were given face-to-face interviews from the Survey Research Lab of the University of Illinois, Chicago in their homes and asked to complete a survey on a laptop computer. The sample design is a multistage, stratified sample. In the first stage, nine Illinois counties were sampled with probabilities proportionate to size (PPS), where the measure of size is the adult population. PPS sampling gives more populous counties a higher probability of selection while still insuring that all counties have some probability of selection. In the second stage, five census tracts were sampled from each of the sampled counties. In the third stage, four blocks were sampled from the sampled census tracts. Census tracts and blocks also were sampled with PPS. Once the blocks were selected, interviewers listed all households on the sampled blocks and completed interviews with five households. Interviewers went to specified households up to 10 times in order to contact residents. The sample was stratified into three age strata that reflect the three age groups from Study 1: 20 - to 39-year-olds $(n=235), 40$ - to 59-year-olds $(n=$ $223)$, and those aged 60 and over $(n=155)$. In order to ensure an equal number of completed interviews within each of these strata, selection procedures at the household level were adjusted to oversample the smallest strata. Response rate, calculated by dividing the number of completed interviews by the total number of interviews, refusals, noncontact of eligible respondents, and a proportion of households whose eligibility status is unknown (i.e., RR3), was $18.5 \%$. Total refusal rate was $21.5 \%$. Participants were given a $\$ 15$ gift card as reimbursement for their time.

The large representative sample of Illinois residents allowed the examination of populations that are not well represented in studies of personality. Nearly one third $(n=202)$ of the sample identified themselves as minorities. Of the ethnic minorities, $2.5 \%$ were American Indian, $17.7 \%$ were of Asian descent, 50.2\% were African American, 7.4\% multiracial, 7.4\% "other," and 14.8\% Hispanic/Latino/Mexican American.

Additionally, the sample consisted of a broad range in household income. Of these participants, $11.3 \%$ made $\$ 10 \mathrm{k}$ or less, $13.3 \%$ made $\$ 10,001-\$ 20 \mathrm{k}, 19.1 \%$ made $\$ 20,001-\$ 30 \mathrm{k}$, $17.2 \%$ made $\$ 30,001-\$ 50 k$, $11.2 \%$ made $\$ 50,001-\$ 70 k$, and
$18.2 \%$ made $\$ 70 \mathrm{k}$ and greater, with $9.7 \%$ refusing to answer or missing. Additionally, there was a broad range in educational attainment. Of the participants, $10.5 \%$ did not complete high school, $25.3 \%$ had a high school education or equivalent, $27.9 \%$ had some college education, with $17.2 \%$ of the sample completing a college degree, and $12.3 \%$ completing at least some graduate work. SES was computed as a linear combination of standardized income, level of education, and job prestige. Two independent coders rated job prestige on the basis of self-reported job title, per Hauser and Warren (1997).

Measures. Because of time constraints, the participants in Study 2 only completed scales from the IPIP-AB5C personality inventory (Goldberg, 1999), which, as seen in Study 1, taps the industriousness, orderliness, and impulse control facets of conscientiousness. Alpha reliabilities for the scales were again good, ranging between .68 and .86, with an average of .77. Correlations between the scales are presented in Table 5 .

\section{Results}

Measurement invariance. As in Study 1, three different forms of measurement invariance for each scale of the AB5C were tested in CFA models. Good fit for the configural invariance model was found for each scale of the AB5C (average IFI = .98 ; average RMSEA = .05). Constraining the factor loadings to be equivalent across groups did not reduce the relative model fit of each model (average IFI $=.97$; average RMSEAs $=.05$ ), based on nonsignificant chi-square difference and RMSEA confidence interval overlap. We next tested scalar invariance by constraining intercepts across groups. As indexed by the chi-square difference, this added constraint did not reduce model fit (average IFI $=.97$; average RMSEA $=.05$ ), with the exception of the scales for rationality, $\Delta \chi^{2}(8)=22.15, p=.01$, and dutifulness, $\Delta \chi^{2}(8)=16.37, p=.04$. However, the RMSEA confidence intervals associated with the metric and scalar invariance models for each scale overlapped, suggesting that the differences in fit for rationality and dutifulness were trivial. On the basis of the RMSEA confidence intervals, both scales were interpreted as having scalar invariance. Taken together, these results indicate that there was measurement equivalence of conscientiousness scales across age groups and that differences between age groups can be meaningfully interpreted.

Mean-level differences in self-reported conscientiousness. We computed differences between age groups to examine cross-sectional age changes in the facets of conscientiousness measured by the AB5C. Table 6 lists the means, standard deviations, effect size estimates, and correlations with age for each consci-

Table 5. Correlations Between Conscientiousness Scales in Study 2

\begin{tabular}{llllllllll}
\hline Scale & 1 & 2 & 3 & 4 & 5 & 6 & 7 & 8 & 9 \\
\hline 1. Purposefulness & .80 & & & & & & & & \\
2. Dutifulness & .66 & .78 & & & & & & & \\
3. Efficiency & .81 & .62 & .84 & & & & & & \\
4. Organization & .70 & .63 & .65 & .80 & & & & & \\
5. Conscientiousness & .78 & .69 & .79 & .68 & .77 & & & & \\
6. Orderliness & .65 & .65 & .67 & .57 & .74 & .78 & & & .58 \\
7. Rationality & .61 & .45 & .64 & .54 & .57 & .54 & .68 & & .78 \\
8. Perfectionism & .51 & .42 & .53 & .65 & .55 & .60 & .60 & .78 & .39 \\
9. Cautiousness & .45 & .48 & .40 & .26 & .42 & .47 & .39 & .24 & .70 \\
\hline
\end{tabular}


Table 6. Study 2 Age Differences

\begin{tabular}{|c|c|c|c|c|c|c|c|}
\hline Conscientiousness facet & Young $M(S D)$ & Middle $M(S D)$ & Older $M(S D)$ & $d_{12}(\mathrm{CI})$ & $d_{23}(\mathrm{CI})$ & $d_{13}(\mathrm{CI})$ & $r(\mathrm{CI})$ \\
\hline Purposefulness & $3.61(0.61)$ & $3.74(0.61)$ & $3.71(0.62)$ & $.21(.06, .37)$ & $-.05(-.23, .13)$ & $0.16(.00, .33)$ & $.09(.01, .17)$ \\
\hline Efficiency & $3.69(0.67)$ & $3.75(0.69)$ & $3.66(0.68)$ & $.09(-.07, .24)$ & $-.13(-.32, .04)$ & $-.04(-.23, .13)$ & $-.01(-.09, .07)$ \\
\hline Organization & $3.93(0.54)$ & $4.04(0.50)$ & $3.95(0.56)$ & $.22(.06, .33)$ & $-.17(-.35, .01)$ & $.04(-.13, .21)$ & $.02(-.06, .10)$ \\
\hline Orderliness & $3.62(0.50)$ & $3.66(0.44)$ & $3.68(0.51)$ & $.09(-.06, .24)$ & $.04(-.13, .20)$ & $.12(-.06, .29)$ & $.06(-.02, .14)$ \\
\hline Rationality & $3.40(0.43)$ & $3.39(0.43)$ & $3.42(0.46)$ & $-.02(-.18, .13)$ & $.07(-.11, .24)$ & $.04(-.14, .21)$ & $.04(.04, .12)$ \\
\hline Conscientiousness & $3.80(0.55)$ & $3.89(0.53)$ & $3.90(0.58)$ & $.17(.01, .32)$ & $.02(-.17, .20)$ & $.18(.01, .35)$ & $.08(.0, .16)$ \\
\hline \multicolumn{8}{|l|}{ Impulse Control } \\
\hline Cautiousness & $3.14(0.56)$ & $3.23(0.59)$ & $3.51(0.53)$ & $.16(.00, .31)$ & $.49(.32, .67)$ & $.68(.49, .86)$ & $.26(.14, .34)$ \\
\hline
\end{tabular}

$n=235$ for Young; $n=223$ for Middle; $n=155$ for Older; $d_{12}=$ standardized mean difference between middle age (40-59) and young age (20-39); $d_{23}=$ standardized mean difference between old age (60 and above) and middle age; $d_{13}=$ standardized mean difference between old-age and young-age groups; $r=$ correlation with age; $\mathrm{CI}=95 \%$ confidence intervals. Bold values indicate $p<.05$.

entiousness scale. The findings were remarkably consistent with the findings of Study 1. Age differences for the scales associated with industriousness were found primarily between young adulthood and middle age $(d=0.24, p<.05)$. The middle-age group scored higher on levels of dutifulness $(d=0.26$, $p<.05)$, purposefulness $(d=0.20, p<.05)$ and organization $(d=$ $0.21, p<.05)$ compared with the young adult group. The scales associated with orderliness did not significantly differ between age groups. Levels of impulse control, as measured by the Cautiousness scale, did not change from young adulthood to middle age $(d=0.16, p<.05)$, but did show a dramatic increase from middle- to old age $(d=0.50, p<.05)$. In terms of replication across studies, the confidence intervals for the $d$ scores can be used to determine whether the effect sizes for the AB5C measure of conscientiousness in Study 2 were outside of the confidence intervals of the effect sizes for the AB5C measure in Study 1 (Cumming, 2008). Although there is some variability in the magnitude of the effects across studies, we found that no effect sizes in Study 2 fell outside of the confidence intervals in Study 1. In terms of the pattern of change, the findings from Study 2 largely replicated Study 1 such that industriousness increased earlier in the lifespan, orderliness changed little with age, and the largest increases were in the domain of impulse control.

Correlations with age also replicated the pattern found in Study 1. Significant correlations occurred for the industriousness composite $(r=.08)$ and two scales that tap industriousness, purposefulness $(r=.09)$, and dutifulness $(r=.15)$. The orderliness composite was not significantly related to age $(r=.06$, $p>.05)$, but two scales that tap the orderliness facet, orderliness $(r=.10)$ and conscientiousness $(r=.08)$, were significantly correlated with age. Impulse control again had the largest correlation with age $(r=.26)$. Curvilinear effects were found for industriousness by regressing each scale on age squared. The industriousness composite $(\beta=-.14, p<.05)$ and the scales of purposefulness $(\beta=-.11, p<.05)$, dutifulness $(\beta=-.11, p<.05)$, organization $(\beta=-.16, p<.05)$, and conscientiousness $(\beta=-.13$, $p<.05)$ all increased until middle age and then plateaued or slightly decreased in older adulthood.

Age differences in conscientiousness in African Americans. Next, we examined whether African Americans showed the same patterns of age differences in conscientiousness as did the sample as a whole. As a first step, we tested whether African Americans had similar factor structures as Caucasians. Tests of measurement equivalence between the two groups could not be examined across specific ages because of small sample sizes and thus low power. The configural invariance model indicated that the two groups had very similar factor structures for each facet (average IFI = .98; average RMSEA $=.04)$. A second model constrained the factor loadings to be equivalent across groups. This constraint did not result in a significant loss of fit according to chi-square difference tests and RMSEA confidence intervals (average IFI $=.97$; average RMSEA $=.05$ ). The intercepts were then constrained across groups to test scalar invariance. Again, as indexed by the chi-square difference and RMSEA confidence intervals, this added constraint did not reduce model fit for any scale (average IFI $=.97$; average RMSEA $=.05$ ). Taken together, these results indicate that there is measurement equivalence between minority groups as a whole and Caucasians, suggesting that ethnic groups have a similar structure of conscientiousness.

The means for each age group, standard deviations, effect size estimates, and correlations with age for African Americans are presented in Table 7 . The pattern of age changes in conscientiousness found in Study 1 was replicated in African Americans. We performed an ANOVA, with an Age $\times$ Ethnicity interaction, predicting each conscientiousness scale to test whether ethnicity moderated conscientiousness development. No significant interactions were found, indicating that African Americans did not have divergent patterns of age differences compared with their Caucasian counterparts. ${ }^{6}$ Replicating the patterns found in Caucasians, age differences in industriousness occurred primarily during young adulthood. Effect size estimates of the scales tapping industriousness were similar to Study 1 . The middle-aged group scored significantly higher on organization $(d=0.43, p<.05)$. No significant age differences were found for any measure of orderliness. Age differences in impulse control were again found across adulthood, with the older adult group being more controlled than younger adults $(d=0.44, p<.05)$.

6 An additional analysis combined all ethnicities into one group. This group had age trends similar to those in Study 1 and was not significantly different from the Caucasian sample. 
Table 7. Study 2 Age Differences in African Americans

\begin{tabular}{lccccccc}
\hline Conscientiousness facet & Young $M(S D)$ & Middle $M(S D)$ & Old $M(S D)$ & $d_{12}(\mathrm{CI})$ & $d_{23}(\mathrm{CI})$ & $d_{13}(\mathrm{CI})$ & $r(\mathrm{CI})$ \\
\hline Industriousness & $3.93(0.61)$ & $4.05(0.53)$ & $3.94(0.62)$ & $.23(-.14, .61)$ & $-.20(-.60, .2)$ & $.02(-.38, .42)$ & $.04(-.15, .23)$ \\
$\quad$ Purposefulness & $3.78(0.71)$ & $3.82(0.70)$ & $3.77(0.62)$ & $.05(-.32, .43)$ & $-.09(-.57, .38)$ & $-.02(-.45, .35)$ & $-.01(-.20, .18)$ \\
$\quad$ Dutifulness & $4.15(0.59)$ & $4.28(0.50)$ & $4.18(0.59)$ & $.23(-.18, .62)$ & $-.18(-.63, .22)$ & $.07(-.34, .46)$ & $.01(-.18, .20)$ \\
$\quad$ Efficiency & $3.84(0.76)$ & $3.93(0.79)$ & $3.83(0.65)$ & $.12(-.28, .48)$ & $-.15(-.61, .30)$ & $-.02(-.42, .38)$ & $.02(-.17, .21)$ \\
$\quad$ Organization & $3.92(0.65)$ & $4.16(0.53)$ & $3.96(0.76)$ & $.43(.04, .82)$ & $-.30(-.76, .15)$ & $-.01(-.39, .39)$ & $-.04(-.23, .15)$ \\
Orderliness & $3.75(0.54)$ & $3.73(0.44)$ & $3.71(0.53)$ & $-.05(-.45, .35)$ & $-.04(-.39, .49)$ & $-.07(-.43, .30)$ & $-.07(-.26, .12)$ \\
$\quad$ Orderliness & $3.85(0.74)$ & $3.86(0.60)$ & $3.84(0.80)$ & $.01(-.37, .39)$ & $-.02(-.48, .43)$ & $-.01(-.42, .37)$ & $-.03(-.22, .16)$ \\
$\quad$ Perfectionism & $3.78(0.65)$ & $3.77(0.58)$ & $3.68(0.82)$ & $-.0(-.41, .36)$ & $-.14(-.56, .31)$ & $-.14(-.54, .25)$ & $-.08(-.27, .11)$ \\
$\quad$ Rationality & $3.49(0.56)$ & $3.44(0.53)$ & $3.43(0.48)$ & $-.09(-.47, .30)$ & $-.03(-.44, .42)$ & $-.12(-.52, .26)$ & $-.10(-.29, .09)$ \\
$\quad$ Conscientiousness & $3.89(0.58)$ & $3.92(0.64)$ & $3.92(0.65)$ & $.05(-.34, .44)$ & $.00(-.47, .44)$ & $.05(-.35, .43)$ & $-.01(-.20, .18)$ \\
Impulse Control & & & & & & & \\
$\quad$ Cautiousness & $3.26(0.55)$ & $3.41(0.61)$ & $3.51(0.57)$ & $.29(-.13, .69)$ & $.18(-.25, .65)$ &. $.44(.03, .84)$ & $.08(-.11, .27)$ \\
\hline
\end{tabular}

$n=49$ for Young; $n=30$ for Middle; $n=29$ for Old. $d_{12}=$ standardized mean difference between middle age (40-59) and young age (20-39); $d_{23}=$ standardized mean difference between old age ( 60 and above) and middle age; $d_{13}=$ standardized mean difference between old-age and youngage groups; $r=$ correlation with age; $\mathrm{CI}=95 \%$ confidence intervals. Bold values indicate $p<.05$.

SES and conscientiousness. Next, we tested whether people at different levels of SES showed the same patterns of age differences in conscientiousness. We tested this by computing an Age $\times$ Current SES interaction for each conscientiousness scale. If the interaction term is significant, then it indicates that individuals from different levels of SES have different patterns of age differences in conscientiousness. We found no interaction for seven of the nine conscientiousness scales. However, a significant interaction between age and SES emerged for the cautiousness $(\beta=-.081), t(609)=-2.04, p<.05$, and perfectionism $(\beta=-.091), t(609)=-2.81, p<.05$, scales. To investigate the interaction, we plotted the simple slopes of one standard deviation above and below the mean of SES for both cautiousness and perfectionism. As can be seen in Figure 1, age differences in cautiousness were more pronounced in low-SES individuals compared with individuals high in SES. Across both samples, no age differences were found for perfectionism. However, as evidenced by the Age $\times$ SES interaction, age differences occurred at different levels of SES (see Figure 2). Low-SES in-

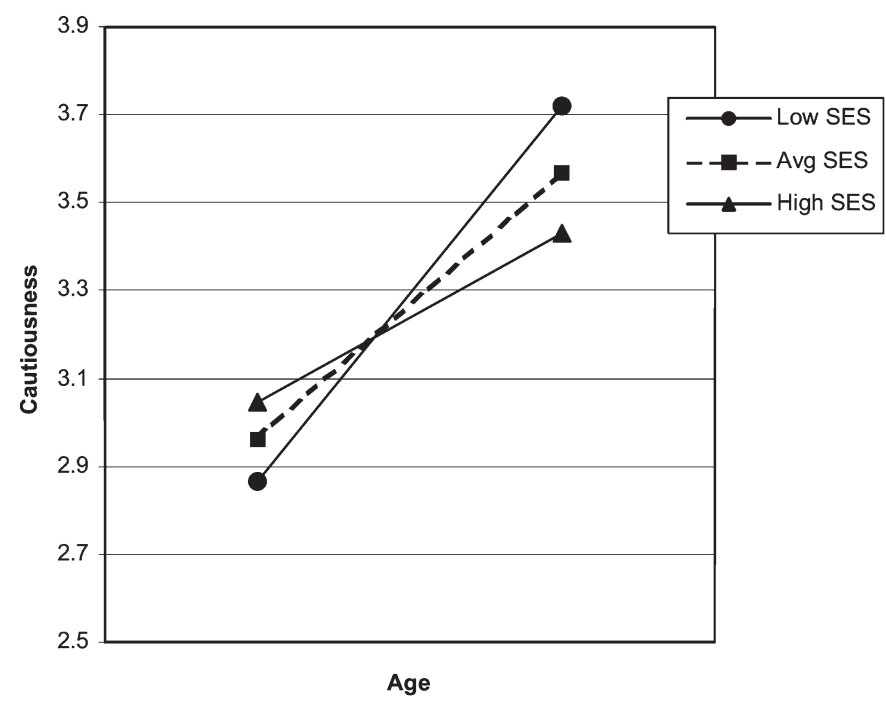

Figure 1. Age difference in cautiousness at different levels of socioeconomic status (SES). Avg = Average. dividuals showed greater levels of perfectionism with age, whereas high-SES individuals had lower levels of perfectionism as age increased.

It should be noted that we found a main effect of SES on levels of dutifulness $(\beta=.17, p<.05)$, efficiency $(\beta=.09, p<$ $.05)$, organization $(\beta=.27, p<.05)$, and conscientiousness $(\beta=$ $.12, p<.05)$. This finding shows that people higher on SES are higher on these indicators of industriousness, but age-related changes remained similar across all levels of SES (i.e., no Age $\times$ SES interaction).

\section{Discussion}

Our results suggest that age differences in conscientiousness exist throughout adulthood and well into old age. Selfreported industriousness, impulse control, and reliability showed age differences from early adulthood to middle age. The transition into late adulthood was characterized by increases in impulse control, reliability, and conventionality.

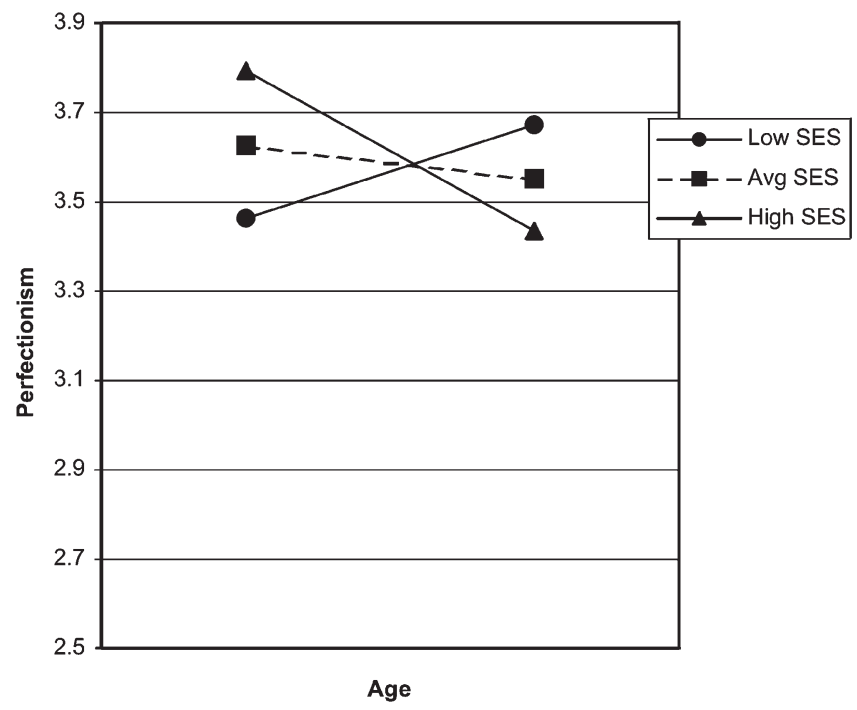

Figure 2. Age difference in perfectionism at different levels of socioeconomic status (SES). 
This implies that changes in conscientiousness found during college (e.g., Robins, Fraley, Roberts, \& Trzesniewski, 2001) and old age (e.g., Dudek \& Hall, 1991) may be reflecting a common core of increasing impulse control and reliability, coupled with age-specific changes in industriousness and conventionality. Because the facets of conscientiousness tend to change at different points in the life course, there is a clear need to go beyond the broad Big Five level of analysis to fully understand the development of conscientiousness.

In contrast to self-reports, no significant increases occurred between young and middle adulthood in observer reports, a time where changes in conscientiousness are usually prevalent (Roberts, Walton, \& Viechtbauer, 2006). Past studies in which a single observer has been used have revealed age-related changes that are smaller in magnitude than self-reports, but usually in the same direction (McCrae et al., 2004). Interestingly, most of these studies have used predominantly young or middle-aged adults. Clearly, the fact that large age differences were perceived between middle-aged and older adults is a finding unique to the present research.

Possible reasons for the different patterns between observer and self-reports likely hinge on the type of information used to make personality judgments. Presumably, people have access to and use their own internal thoughts and feelings when filling out self-reports, whereas observers need to infer personality on the basis of the target's behavior or expressions of thoughts and feelings (Funder, 1995). One explanation for the patterns found here is that shifts in conscientiousness-related internal thoughts and feelings may be quite salient to the people when transitioning through young and middle adulthood but that these internal features of conscientiousness are not salient to observers. Thus, people may see themselves as more conscientious, and report accordingly, but the behaviors reflecting increased conscientiousness may not necessarily align with their self-perception. That is, the actual behaviors and external cues that indicate higher levels of conscientiousness take longer to manifest than the thoughts and feelings associated with conscientiousness. Another possibility is that observers are slower to attribute changes to others than to themselves. This skepticism would lead to the inference that reputations are more difficult to change than are self-perceptions. Future research should test these various interpretations in order to determine the source of the differential patterns across selfand observer reports of personality traits.

We found the patterns of self-reported age differences replicated using a representative sample of the state of Illinois. Two important generalizations were drawn from this sample. First, results from samples that are not representative appear to generalize to broader and more diverse populations. Second, age differences replicated in African Americans and across varying levels of SES for most facets of conscientiousness. However, a few facets were moderated by SES. Individuals with low levels of SES were lower in conscientiousness in young adulthood but had higher levels of conscientiousness in old age, compared with individuals high in SES. This may reflect a delayed normative developmental pattern in which people with fewer means are not afforded opportunities for normative investment in institutions, such as work and marriage, until later ages. Similarly, men who were jailed in adolescence and young adulthood showed increases in conscientiousnessrelated traits, but at a later age than men who followed a more normative path of development (Morizot \& Le Blanc, 2003).
Why do facets develop differently? The differences found in developmental trajectories of conscientiousness facets naturally raise the question of why these unique patterns exist. That is, if conscientiousness is a meaningful and coherent trait, then why do the facets of conscientiousness have different age trajectories? One possibility is that the mechanisms behind change are focused at the facet level rather than at the broad Big Five level.

Changes in personality traits are thought to occur mainly through contingencies found in the environment. Social roles such as occupations, romantic relationships, and family interactions each come with certain expectations for how to behave-either explicit expectations, such as being told what to do, or by more subtle expectations, such as through watching and listening to others (see Roberts \& Caspi, 2003; Roberts, Wood, \& Caspi, 2008). This does not mean that biological processes do not play a role in personality development (Roberts \& Jackson, in press). Genetic processes are thought to influence both the likelihood of experiencing certain environments (gene-environment correlations [rGE]; Jaffee \& Price, 2007) and the response to particular environments (gene-environment interaction [G×E]; Caspi \& Moffitt, 2006). It is likely that these environmental contingencies and expectations are facet specific, rather than at a broader Big Five factor level (McCrae et al., 2008).

For example, in many cultures the transition from young to middle adulthood is a time when people are expected to initiate a career and establish a family (Havighurst, 1952). Workrelated contingencies and expectations most likely focus on industriousness rather than on conscientiousness broadly defined. This is because hard work cannot be easily delayed or dismissed after beginning a legitimate career track. Not living up to expectations could create large repercussions that may result in being passed over for a promotion or even fired, which would then strain financial needs and personal relationships. After establishing oneself in a comfortable adult work role, the expectancies to be increasingly industrious may wane.

Investments in career and family roles most likely provide continuous rewards for being reliable and self-controlled (e.g., Neyer \& Asendorpf, 2001; Roberts \& Bogg, 2004). Showing up to work on time and waking up to care for a sick child, for example, will be rewarded within these roles regardless of when they occur in the life course. As time passes, expectations are thought to become more demanding. This can occur through obtaining new investments or by expanding on previously held roles. For example, new expectations on how to behave occur when becoming a parent. Likewise, across time, there might be greater expectations within a specific role, such as through being promoted and having more responsibilities. Thus, as time goes on, being impulsive and unreliable can result in larger opportunity costs. With more to lose, either through the career or through the family one has worked long and hard for, the greater the expectations are for controlling impulses and being reliable.

In contrast to the other conscientiousness facets, conventionality may not be rewarded in early adulthood. This could be because thinking outside the box and individuality are prerequisites for the establishment of a mature adult personality, at least in Western cultures (Dollinger \& Dollinger, 1997). However, with age, people may become more invested in their ideals and solidify their views of life. This can lead to difficulty in seeing the benefits of new ways of thinking and behaving. 
A parallel is the tendency to become more politically conservative with age (Campbell \& Strate, 1981).

Implications for allied fields. Understanding the development of conscientiousness can be an important factor in a number of domains such as health (Friedman et al., 1993; Hampson, Goldberg, Vogt, \& Dubanoski, 2007), social relationships (Asendorpf \& Wilpers, 1998), and criminality (Miller \& Lynam, 2001). The connection between conscientiousness and longevity, health, social relationships, and prosocial behaviors most likely arises because people who are more conscientious create life paths that indirectly promote these outcomes. The development of conscientiousness becomes more important when considering that the relationship between life outcomes and conscientiousness is reciprocal. Participation in behaviors linked to health or criminal acts, for example, are associated with changes in conscientiousness (Roberts \& Bogg, 2004; Roberts, Bogg, Walton, \& Caspi, 2006). This implies that to understand, or even promote, changes in domains related to conscientiousness, the development of conscientiousness needs to be explored further.

Changes in conscientiousness are additionally important when considering that changes in personality, above and beyond the initial level, have been linked to important life outcomes. For example, changes of one half of a standard deviation on neuroticism predicted a $37 \%$ increase in mortality in an older sample (Mroczek \& Spiro, 2007). Increases in conscientiousness have also been associated with better health outcomes above and beyond initial levels (Mroczek et al., 2008). Our results suggest that focusing on certain facets of conscientiousness may find even greater changes and possibly greater ramifications. Specifically, one of the most important facets for health, impulsivity, had an average difference of about three fourths a standard deviation between young and older adulthood. On the basis of the effects of a half-standard deviation increase in neuroticism, a three fourths standard deviation increase in impulse control may be literally adding years to people's lives.

Additionally, our facet-level analysis can help explain various developmental trends in related fields. For example, in criminal behavior, there is a tendency for criminals to "burn out," with the frequency of criminal acts declining with age, even after controlling for factors such as previous criminal records (Hoffman \& Beck, 1984; Laub \& Sampson, 2001). Explanations for recidivism have mainly focused on the decreased opportunities and social influences that contribute to crime (Gottfredson \& Hirschi, 1990), partially based off the assumption that internal propensities to criminal behavior are stable across the life course. Because one of the primary personality traits associated with criminal behaviors is conscientiousness (Miller \& Lynam, 2001), it is possible that criminal behaviors decrease with age because of the normative increases found in impulse control.

\section{Limitations}

Despite having multiple samples and assessing them with multiple measures, these studies have some limitations that suggest further research. First, because these studies were cross-sectional, it is possible that the age differences do not reflect normative development, but rather are the result of cohort effects. These findings must be replicated across multiple samples and historical periods. However, there is evidence to suggest that these cross-sectional differences reflect true developmental processes and that the findings would replicate longitudinally. Longitudinal and cross-sectional studies report similar developmental trends for personality traits across adulthood (Roberts, Robins, Caspi, Trzesniewski, 2003; Terracciano, McCrae, Brant, \& Costa, 2005). Cross-cultural replication of personality trait development has also mitigated the claim that history and cohort effects solely drive personality development (McCrae et al., 1999).

This is not to say that cohort is unimportant to the changes we found in conscientiousness. Recent meta-analytic research showed that individuals who entered young adulthood in the 1960s failed to increase in conscientiousness as much as those born earlier or later in the 20th century (Roberts, Walton, \& Viechtbauer, 2006). One possibility is that experiencing the social climate of the late ' 60 s and '70s during young adulthood led to smaller increases in conscientiousness (Roberts, Walton, \& Viechtbauer, 2006) and even possible decreases in conscientious-related traits (Helson, Jones, \& Kwan, 2002; Roberts \& Helson, 1997). Interestingly, individuals entering young adulthood in the 1960s would have been in the old-age group in our sample. Thus, it is possible that cohort may have diminished the magnitude of the change found in these two samples because the older groups came of age in the 1960s. Unfortunately, the veracity of this inference will have to await more facet-level studies of conscientiousness across the life course of different cohorts.

Another limitation is the difficulties that are associated in assessing facets. Part of the difficulty inherent in identifying and measuring facets is that they are not orthogonal. Because overlap among facets is inevitable, it is difficult to demarcate the ideal number of facets or content for each facet. Our five facets were identified through two different assessment techniques and can be thought of as a preliminary lower order structure of conscientiousness. Other facets that have been proposed (e.g., decisiveness, virtue) await further research. In addition to coming to a consensus on the number of lower order facets, there are difficulties associated with assessing facets. We used a measure developed to assess the five facets as well as an existing measure, the AB5C. Because the scales of the AB5C were not explicitly developed to align with the five facets, some scales are better at measuring a single facet than others, and some scales might measure more than one facet. However, factor analyses of the AB5C scales do load highly on the five facets of conscientiousness and constitute a viable assessment measure (Roberts, Chernyshenko, et al., 2005).

\section{Conclusion}

We examined age differences in conscientiousness at a facet level of analysis in the present study, using both self- and observer reports, and with representative samples. We found that not all facets of conscientiousness change similarly. It is proposed that only through focusing on lower levels of analysis and taking a multimethod approach can we begin to go beyond patterns of development to identifying the processes behind increases in conscientiousness. With the strong relationship between conscientiousness and many significant life outcomes, increases in conscientiousness could add years to one's life, dollars to one's pocket, and provide happiness to one's home. 


\section{References}

Allemand, M., Zimprich, D., \& Hertzog, C. (2007). Cross-sectional age differences and longitudinal age changes of personality in middle adulthood and old age. Journal of Personality, 75, 1-36.

Asendorpf, J. B., \& Wilpers, S. (1998). Personality effects on social relationships. Journal of Personality and Social Psychology, 74, 1531- 1544.

Baltes, P. B., \& Smith, J. (2003). New frontiers in the future of aging: From successful age of the young old to the dilemmas of the fourth age. Gerontology, 49, 123-135.

Brim, O. G. (2000). MacArthur foundation study of successful midlife development. ICPSR Bulletin, XX, 1-12.

Campbell, J. C., \& Strate, J. (1981). Are older people conservative? Gerontologist 21, 580-591.

Caspi, A., \& Moffitt, T. E. (2006). Gene-environment interaction research and neuroscience: A new partnership? Nature Reviews Neuroscience, 7, 583-590.

Cohen, J. (1992). A power primer. Psychological Bulletin, 112, 155-159.

Costa, P. T., Jr., \& McCrae, R. R. (1988). Personality in adulthood: A six-year longitudinal study of self-reports and spouse ratings on the NEO Personality Inventory. Journal of Personality and Social Psychology, 54, 853-863.

Costa, P. T., Jr., \& McCrae, R. R. (1992). Revised NEO Personality Inventory (NEO-PI-R) and NEO Five-Factor Inventory (NEO-FFI) professional manual. Odessa, FL: Psychological Assessment Resources.

Cumming, G. (2008). Replication and $p$ intervals: $p$ values predict the future only vaguely, but confidence intervals do much better. Perspectives on Psychological Science, 3, 286-300.

Dollinger, S. J., \& Dollinger, S. M. J. (1997). Individuality and identity exploration: An autophotographic study. Journal of Research in Personality, 31, 337-354.

Dudek, S. Z., \& Hall, W. B. (1991). Personality consistency: Eminent architects 25 years later. Creativity Research Journal, 4, 213-231.

Fiske, D. W. (1971). Measuring the concepts of personality. Chicago: Aldine Publishing.

Friedman, H. S., Tucker, J. S., Tomlinson-Keasey, C., Schwartz, J. E., Wingard, D. L., \& Criqui, M. H. (1993). Does childhood personality predict longevity? Journal of Personality and Social Psychology, 65, 176-185.

Funder, D. C. (1995). On the accuracy of personality judgment: A realistic approach. Psychological Review, 102, 652-670.

Goldberg, L. R. (1993). The structure of phenotypic traits. American Psychologist, 48, 26-34.

Goldberg, L. R. (1999). A broad-bandwidth, public domain, personality inventory measuring the lower-level facets of several five-factor models. In I. Mervielde, I. Deary, F. De Fruyt, \& F. Ostendorf (Eds.), Personality psychology in Europe (Vol. 7, pp. 7-28). Tilburg, the Netherlands: Tilburg University Press.

Gottfredson, M. R., \& Hirschi, T. (1990). A general theory of crime. Stanford, CA: Stanford University Press.

Hampson, S. E., Goldberg, L. R., Vogt, T. M., \& Dubanoski, J. P. (2007). Mechanisms by which childhood personality traits influence adult health status: Educational attainment and healthy behaviors. Health Psychology, 26, 121-125.

Hauser, R. M., \& Warren, J. R. (1997). Socioeconomic indexes for occupations: A review, update, and critique. Sociological Methodology, $27,177-298$.

Havighurst, R. J. (1952). Developmental tasks and education. New York: David McKay.

Heckhausen, J., Dixon, R. A., \& Baltes, P. B. (1989). Gains and loses in development throughout adulthood as perceived by different age groups. Developmental Psychology, 25, 109-121.

Helson, R., Jones, C., \& Kwan, V. S. (2002). Personality change over 40 years of adulthood: Hierarchical linear modeling analyses of two longitudinal samples. Journal of Personality and Social Psychology, $83,752-766$.

Helson, R., \& Kwan, V. S. (2000). Personality development in adulthood: The broad picture and processes in one longitudinal sam- ple. In S. Hampson (Ed.), Advances in personality psychology (Vol. 1, pp. 77- 106). London: Routledge.

Helson, R., Pals, J. L., \& Solomon, M. (1997). Is there adult development distinctive to women? In R. Hogan, J. A. Johnson, \& S. R. Briggs (Eds.), Handbook of personality psychology (pp. 291-314). San Diego, CA: Academic Press.

Helson, R., \& Wink, P. (1992). Personality change in women from the early 40s to the early 50s. Psychology and Aging, 7, 46-55.

Hoffman, P. B., \& Beck, J. L. (1984). Burnout-Age at release from prison and recidivism. Journal of Criminal Justice 12, 617-623.

Hofstee, W. K. B., de Raad, B., \& Goldberg, L. R. (1992). Integration of the Big Five and circumplex approaches to trait structure. Journal of Personality and Social Psychology, 63, 146-163.

Horn, J. L., \& McArdle, J. J. (1992). A practical and theoretical guide to measurement invariance in aging research. Experimental Aging Research, 18, 117-144.

Hu, L., \& Bentler, P. M. (1999). Cutoff criteria for fit indexes in covariance structure analysis: Conventional criteria versus new alternatives. Structural Equation Modeling, 6, 1-55.

Jaffee, S. R., \& Price, T. S. (2007). Gene-environment correlations: A review of the evidence and implications for prevention of mental illness. Molecular Psychiatry, 12, 432-442.

John, O. P., \& Srivastava, S. (1999). The Big Five trait taxonomy: History, measurement, and theoretical perspectives. In L. A. Pervin \& O. P. John (Eds.), Handbook of personality: Theory and research (2nd ed., pp. 102-138). New York: Guilford Press.

Judge, T. A., Martocchio, J. J., \& Thoresen. C. J. (1997). Five-factor model of personality and employee absence. Journal of Applied Psychology, 82, 745-755.

Kolar, D. W., Funder, D. C., \& Colvin, C. R. (1996). Comparing the accuracy of personality judgments by the self and knowledgeable others. Journal of Personality, 64, 311-337.

Laub, J. H., \& Sampson, R. J. (2001). Understanding desistance from crime. Crime and Justice: A Review of Research, 28, 1-69.

Little, T. D., Cunningham, W. A., Shahar, G., \& Widaman, K. F. (2002). To parcel or not to parcel: Exploring the question, weighing the merits. Structural Equation Modeling, 9, 151-173.

Lodi-Smith, J. L., \& Roberts, B. W. (2007). Social investment and personality: A meta-analytic analysis of the relationship of personality traits to investment in work, family, religion, and volunteerism. Personality and Social Psychology Review, 11, 68-86.

MacCallum, R. C., Browne, M. W., \& Sugawara, H. M. (1996). Power analysis and determination of sample size for covariance structure modeling. Psychological Methods, 1, 130-149.

McAdams, D. P. (1993). The stories we live by: Personal myths and the making of the self. New York: Morrow.

McCrae, R. R., Costa, P. T., Jr., Pedroso de Lima, M., Simoes, A., Ostendorf, F., Angleitner, A., et al. (1999). Age differences in personality across the adult life span: Parallels in five cultures. Developmental Psychology, 35, 466-477.

McCrae, R. R., Costa, P. T., Jr., Hrebickova, M., Urbanek, T., Martin,. T. A., Oryol, V. E., et al. (2004). Age differences in personality traits across cultures: Self-report and observer perspectives. European Journal of Personality, 18, 143-157.

McCrae, R. R., \& John, O. P. (1992). An introduction to the five-factor model and its applications. Journal of Personality, 60, 175-215.

McCrae, R. R., Yamagata, S., Jang, K. L., Riemann, R., Ando, J., Ono, Y., et al. (2008). Substance and artifact in the higher-order factors of the Big Five. Journal of Personality and Social Psychology, 95, 442-455.

Meredith, W. (1993). Measurement invariance, factor analysis, and factorial invariance. Psychometrika, 58, 525-543.

Miller, J. D., \& Lynam, D. (2001). Structural models of personality and their relation to antisocial behavior: A meta-analytic review. Criminology, 39, 765-798.

Morizot, J., \& Le Blanc, M. (2003). Searching for a developmental typology of personality and its relations to antisocial behavior: A longitudinal study of adjudicated men sample. Criminal Behavior and Mental Health, 13, 241-277. 
Mount, M. K., Barrick, M. R., \& Strauss, J. P. (1994). Validity of observer ratings of the Big Five personality dimensions. Journal of Applied Psychology, 79, 272-280.

Mroczek, D. K., \& Spiro, A. (2007). Personality change influences mortality in older men. Psychological Science, 18, 371-376.

Mroczek, D. K., Turiano, N., Pitzer, L., Karlamangla, A., Singer, B., \& Ryff, C. D. (2008). Personality trait level and change as predictors of health outcomes: Findings from a national study of Americans (MIDUS). Unpublished manuscript.

Neyer, F. J., \& Asendorpf, J. B. (2001). Personality-relationship transaction in young adulthood. Journal of Personality and Social Psychology, 81, 1190-1204.

Roberts, B. W., \& Bogg, T. (2004). A 30-year longitudinal study of the relationships between conscientiousness-related traits, and the family structure and health-behavior factors that affect health. Journal of Personality, 72, 325-354.

Roberts, B. W., Bogg, T., Walton, K., \& Caspi, A. (2006). De-investment in work and non-normative personality trait change in young adulthood. European Journal of Personality, 20, 461-474.

Roberts, B. W., Bogg, T., Walton, K., Chernyshenko, O., \& Stark, S. (2004). A lexical approach to identifying the lower-order structure of conscientiousness. Journal of Research in Personality, 38, 164-178.

Roberts, B. W., \& Caspi, A. (2003). The cumulative continuity model of personality development: Striking a balance between continuity and change in personality traits across the life course. In R. M. Staudinger \& U. Lindenberger (Eds.), Understanding human development: Lifespan psychology in exchange with other disciplines (pp. 183-214). Dordrecht, the Netherlands: Kluwer Academic.

Roberts, B. W., Caspi, A., \& Moffitt, T. (2001). The kids are alright: Growth and stability in personality development from adolescence to adulthood. Journal of Personality and Social Psychology, 81, 670-683.

Roberts, B. W., Chernyshenko, O., Stark, S., \& Goldberg, L. (2005). The structure of conscientiousness: An empirical investigation based on seven major personality questionnaires. Personnel Psychology, $58,103-139$.

Roberts, B. W., Harms, P. D., Smith, J., Wood, D., \& Webb, M. (2006). Methods in personality psychology. In M. Eid \& E. Diener (Eds.), Handbook of psychological assessment: A multimethod perspective (chap. 22, pp. 321-335). Washington, DC: American Psychological Association.

Roberts, B. W., \& Helson, R. (1997). Changes in culture, changes in personality: The influence of individualism in a longitudinal study of women. Journal of Personality and Social Psychology, 72, 641-651.

Roberts, B. W., \& Jackson, J. J. (in press). Sociogenomic personality psychology. Journal of Personality.

Roberts, B. W., Kuncel, N., Shiner, R. N., Caspi, A., \& Goldberg, L. (2007). The power of personality: A comparative analysis of the predictive validity of personality traits, SES, and IQ. Perspectives in Psychological Science, 2, 313-345.

Roberts, B. W., Robins, R. W., Caspi, A., \& Trzesniewski. K. (2003). Personality trait development in adulthood. In J. Mortimer \& M. Shanahan (Eds.), Handbook of the life course (pp. 579-598). New York: Kluwer Academic.
Roberts, B. W., Walton, K. E., \& Bogg, T. (2005). Conscientiousness and health across the life course. Review of General Psychology, 9, 156-168.

Roberts, B. W., Walton, K. E., \& Viechtbauer, W. (2006). Patterns of mean-level change in personality traits across the life course: A meta-analysis of longitudinal studies. Psychological Bulletin, 132, $1-25$.

Roberts, B. W., Wood, D, \& Caspi, A. (2008). Personality development. In O. P. John, R. W. Robins, \& L. A. Pervin (Eds.), Handbook of personality: Theory and research (3rd ed., chap. 14, pp. 375-389). New York: Guilford Press.

Robins, R. W., Fraley, R. C., Roberts, B. W., \& Trzesniewski, K. (2001). A longitudinal study of personality change in young adulthood. Journal of Personality, 69, 617-640.

Saucier, G. (1994). Mini-markers: A brief version of Goldberg's unipolar Big-Five markers. Journal of Personality Assessment, 63, 506-516.

Siegler, I. C., Costa, P. T., Brummett, B. H., Helms, M. J., Barefoot, J. C., Williams, R. B., et al. (2003). Patterns of change in hostility from college to midlife in the UNC Alumni Heart Study predict highrisk status. Psychosomatic Medicine, 65, 738-745.

Small, B. J., Hertzog, C., Hultsch, D. F., \& Dixon, R. A. (2003). Stability and change in adult personality over 6 years: Findings from the Victoria Longitudinal Study. Journal of Gerontology: Psychological Sciences, 58, 166-176.

Spain, J. S., Eaton, L. G., \& Funder, D. C. (2000). Perspective on personality: The relative accuracy of self versus others for the prediction of behavior and emotion. Journal of Personality, 68, 837-867.

Srivastava, S., John, O. P., Gosling, S. D., \& Potter, J. (2003). Development of personality in early and middle adulthood: Set like plaster or persistent change? Journal of Personality and Social Psychology, 84, 1041-1053.

Tellegen, A., \& Waller, N. (1994). Exploring personality through test construction: Development of the Multidimensional Personality Questionnaire. In S. R. Briggs \& J. M. Cheek (Eds.), Personality measures: Development and evaluation (Vol. 1, pp. 133-161). Greenwich, CT: JAI Press.

Terracciano, A., McCrae, R. R., Brant, L. J., \& Costa, P. T. (2005). Hierarchical linear modeling analyses of the NEO-PI-R scales in the Baltimore Longitudinal Study of Aging. Psychology and Aging, 3, 493-506.

Vandenberg, R. J., \& Lance, C. E. (2000). A review and synthesis of the measurement invariance literature: Suggestions, practices, and recommendations for organizational research. Organizational Research Methods, 3, 4-70.

Watson, D., \& Humrichouse, J. (2006). Personality development in emerging adulthood: Integrating evidence from self-ratings and spouse ratings. Journal of Personality and Social Psychology, 91, 959-974. 